\title{
SIMULATION INCREASES EFFICIENCY OF ENGINE AIR-LEAK TESTING
}

\author{
Ravi Lote \\ Edward J. Williams \\ Onur M. Ülgen \\ PMC \\ 15726 Michigan Avenue \\ Dearborn, Michigan 48126 U.S.A. \\ \{rlote | ewilliams |ulgen\}@pmcorp.com
}

\section{KEYWORDS}

Discrete-event simulation, manufacturing process simulation, bottleneck analysis

\begin{abstract}
Discrete-event process simulation has long since earned its place as one of the most powerful and frequently applicable analytical tools available for production process analysis and improvement. Also, the manufacturing economic sector has rapidly become more competitive, requiring both greater economy and greater efficiency of operations. In the present application of simulation, a Tier I automotive industry supplier, beset with these economic pressures, sought to improve the productivity and efficiency of a test-\&inspection line being designed for an automotive engine plant. Simulation was successfully used to design this line to meet stringent requirements of productivity, low original equipment cost, and low operating cost. Via comparison of multiple alternatives, this simulation study identified potential bottlenecks and produced recommendations for their improvement or removal.
\end{abstract}

\section{INTRODUCTION}

Simulation has long been a mainstay of manufacturing improvement - historically its first major economic sector of application (Miller and Pegden 2000). In the large and complex automotive industry, it is a commonplace that the major automotive manufacturers enlist engineering firms with specialized expertise to design production lines for installation and subsequent operation. These engineering firms, like production companies which supply vehicle parts directly to the automobile manufacturers, are called "Tier I" suppliers. The engineering firms likewise call upon the experience and expertise of industrial engineering firms to obtain the benefit of consultation on lean manufacturing, process simulation, value-stream mapping, and ergonomics. This context is one of many in which simulation has become a key analytical tool in the automotive industry (Ülgen and Gunal 1998).

In the simulation study described here, the client company, an engineering company, sought the help of simulation to design an engine test line for an engine plant of an automaker. This test line is responsible for performing air tests on engines to check for leaks, making needed repairs on engines which fail this test, re-testing the engines after repair, and rejecting the very few engines that still fail after repeated repair efforts. In a broader context, engine plants, which send their output to vehicle final-assembly plants, are a vital link in the intra-company supply chain of any vehicle manufacturer.

Simulation is a powerful tool for analysis of a manufacturing system such as this one, which involves complex routing logic, installation of expensive equipment, incorporation of material-handling equipment (pallets, conveyors), and a strict requirement not to become the bottleneck in a larger process - here, the overall engine assembly process, which in turns supplies the vehicle assembly process in other automotive plants. Accordingly, numerous examples of such simulation studies appear in the literature. For example, Chramcov and Daníček improved the manufacture of short gun barrels using simulation (Chramcov and Daníček 2009). Improvement of both the manufacture and the material handling of forged metal components was documented in (Lang, Williams, and Ülgen 2008). Illustrating the versatility of simulation when applied to manufacturing, Walker, Mebrahtu, and Strange used it to achieve high efficiency in electronics manufacturing over a period of years during which production was mandated to gradually decrease (Walker, Mebrahtu, and Strange 2005).

\section{OVERVIEW OF TESTING OPERATION}

The system studied was the air-leak test area; to which the main lines manufacturing engines send them. As shown in Figure 1 below, engines arriving on pallets from the main line enter the test area via the first of three Life \& Rotate stations, "Lift \& Rotate 1." An arriving engine is then sent preferentially to Air Test Station East ("T1") if there is sufficient vacant capacity on the conveyor preceding it. Failing that, the engine travels to Air Test Station Center ("T2") if there is sufficient vacant capacity on the conveyor preceding it. 
Otherwise,

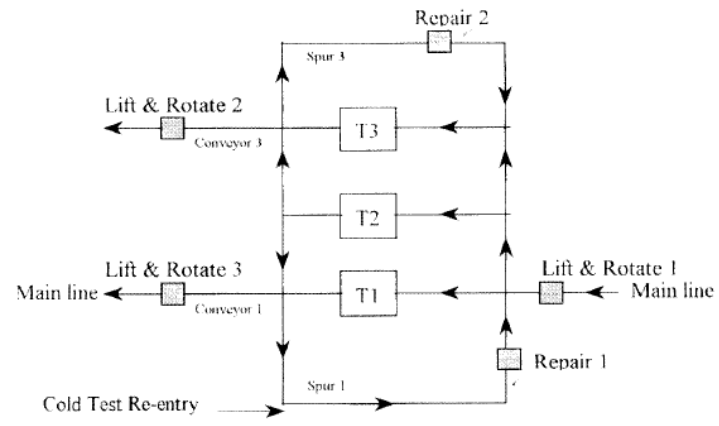

Figure 1. Layout of Stations and Conveyors

the engine proceeds to Air Test Station West ("T3"). Note that "T1" is actually on the "main line" leading from the engine assembly area to the cold-test area; "T2" and "T3" are on spur lines. Engines tested and passed at "T1" and "T3" exit the system (i.e., proceed to the downstream Cold Test area) via Conveyor 1 or Conveyor 3 respectively. Engines tested and passed at "T2" are routed alternately to Conveyor 1 or Conveyor 3. If either conveyor is full and the other is not, the engine will be routed to the available conveyor notwithstanding the "alternating" policy. Engines tested and rejected at "T1" and "T3" recirculate on Spur 1 or Spur 3 respectively. An engine which fails at "T2" is routed to one of these spurs using logic exactly analogous to the logic for choice of Conveyor 1 or Conveyor 3 for engines which pass at "T2."

An engine which fails the test once recirculates without repair work being done (even through it passes through a repair station, either Repair 1 or Repair 2) and is retested. This long-standing policy is a tacit acknowledgment that a test failure - although certainly requiring further checking and perhaps engine repair arises from a fault in the test stand more often than it exposes an actual leak in the engine being tested. An engine which fails twice receives repair service at the repair station through which it passes. An engine which fails a third time is manually removed from its pallet and exits the system; the empty pallet continues circulating in the system. In the first phase of the study, the gradual (gradual because it is rare for any one engine to fail three times) accumulation of empty pallets circulating in the system was ignored. Such "benign neglect" of empty pallets constituted a conservative assumption, helping to establish a "worst case" lower bound scenario for system control logic performance. As will be detailed in the Model Results section (below), the primary focus of this study was the investigation of four control-logic proposals and their ability to meet system throughput targets. Later, the actual operational practice of manually reloading an empty pallet with a newly arriving engine (involving brief use of labor) was added to the model. Engines emerging from Repair 1 first try to enter the conveyor preceding "T1;" failing that, they travel to the conveyor preceding "T2." If that conveyor is also full, the engine travels to the "T3" conveyor section. All engines emerging from Repair 2 go to the "T3" conveyor section. Engines are pushed into and pulled from the repair stations by a dedicated operator. Engines entering a test station for the first time and engines entering after repair have equal priority, and hence these queues are first-come-first-served throughout.

\section{MODEL CONSTRUCTION, VERIFICATION, AND VALIDATION}

In keeping with good simulation analysis practice (Chung 2004), the client engineers and the simulation analysts documented agreed-upon assumptions, the most significant of which were:

1. Target system throughput 171.4 jobs per hour $(\mathrm{JPH})$, corresponding to a target system cycle time of 21 seconds

2. No model mix included in study

3. Labor and needed subassemblies always available

4. Engines leaving the system encounter no blockage

5. No differences among shifts in processing

Process data, including machine cycle times, conveyor capacities and speeds, time between failures, and time to repair were available from client records. The machine cycle times and the conveyor speeds were modeled as constants. Distribution-fitting techniques (Seila, Ceric, and Tadikamalla 2003) suggested modeling times between failures as exponential and times to repair as symmetric triangular (minimum = mean $* 0.9$, mode $=$ mean, maximum $=$ mean $* 1.1)$. The process data also included observation and confirmation of local "right-of-way" policies at the conveyor intersections. For example, if an engine moving "north" in Figure 1 from Lift \& Rotate 1 and an engine moving "south" from Repair 2 competed for routing "westward" to "T3," the engine proceeding from Lift \& Rotate 1 had priority. Client and consultant engineers jointly chose the WITNESS ${ }^{\circledR}$ simulation software for model development. This software provides constructs for machines and conveyors, accommodates complex queuing logic, has convenient arrangements for modeling time-to-fail and time-to-repair, and supports concurrent development of a simulation model and its animation (Mehta and Rawles 1999). A screen snapshot of the model appears in Figure 2, in the Appendix.

More subtly, high importance was attached to an investigation of whether engine failure in the air-leak test occurred randomly. If engine failures tended to cluster in time, the air-leak test area would surely be overloaded during those time intervals, and correspondingly underutilized at other times. Accordingly, the time sequence of engine test results (conceptually "P" for "pass" and "F" for "fail") were subjected to a statistical runs test for independence (Sprent and Smeeton 2007). The result of this test 
indicated randomness of engine leak-test failure (as opposed to the suspected positive correlation [clustering]) at the 5\% significance level. Therefore, the failure probability desired for each experimental scenario was treated as the parameter of a binomial distribution, in accordance with the binomial presumption of independent trials.

Various verification and validation techniques were used during this project (Sargent 2004). They included sending one engine through the model, temporarily eliminating all randomness from the model (and then checking output against Microsoft Excel ${ }^{\circledR}$ computations), viewing the animation with the client engineers, and performing directional tests (e.g., increasing arrival rate and/or cycle times, and checking that queue lengths and wait times likewise increase). After routine error identification and correction, the model achieved credibility with the client engineers and their management.

\section{MODEL RESULTS}

All model runs were made on a steady-state basis, since the actual engine air-leak test line (like the upstream engine assembly line and the downstream engine coldtest line) typically run multiple shifts, and do not "empty and clear" themselves between shifts (work remains in situ between shifts). Four experimental scenarios, each using a different control logic algorithm, were considered, as described next; within each, three different and plausible reject rates were compared. These subdivisions of the four experiments reflect the uncertainty of the eventual reject rates, and therefore constitute a sensitivity analysis (Zeigler, Praehofer, and Kim 2000). Each of the twelve distinct experimental situations was run for ten replications, and each replication used a warm-up time of 100 hours and a data-collection run length of 1000 hours.

Experiment 1 represented the proposed Air-Leak Test line in isolation, with reject rates of $23 \%, 15 \%$, or $10 \%$ (these reject rates were taken from a previous successful simulation study of an analogous engine test area performed for the same client). In this experiment, all engines (whether good or rejected) leaving the test machines were routed alternately to the east and west conveyors. Hence this experiment was fundamentally "impractical," and was considered a base-case benchmark, a conceptually convenient "zero point" for consideration of alternatives. In this experiment, engines entered the model only from the upstream assembly line.

Experiment 2 represented the proposed air-leak test line in isolation, with reject rates of $22 \%, 20 \%$, and $18 \%$. In this experiment, $75 \%$ of rejects leaving the air test center were routed to Repair 1, with the remaining 25\% routed to Repair 2. Satisfactory engines leaving the air test center were alternately routed to the east and west exit conveyors. As was the case for experiment 1, engines entered this model only from the upstream assembly line.

Unlike experiments 1 and 2, experiment 3 represented a new system comprising two sub-systems: the proposed air-leak test line, and a black-box representation of all upstream engine-assembly processes. An engine interarrival rate of 21 seconds was added to represent this black box, with removal of the "engines always available" assumption used in the first two experiments. Reject rates were set at $20 \%, 18 \%$, and $16 \%$. Half of the rejects leaving the testing machines were routed to Repair 1, and half to Repair 2. Satisfactory engines were routed alternately to the east and west exit conveyors, as in experiment 2 . Further, in this experiment, logic was added to the model to reintroduce empty pallets and engines which failed cold test into the air-leak test area.

Experiment 4, like experiments 1 and 2, represented the air-leak test line in isolation, with reject rates at $20 \%$, $18 \%$, and $16 \%$. Half of the rejects leaving the testing machines were routed to Repair 1, and half to Repair 2, as in experiment 3. Satisfactory engines leaving the air test center were alternately routed to the east and west exit conveyors, as in experiment 2 . Also, in this experiment, the logic added to the model in experiment 3 (re-introducing empty pallets and engines which failed cold test into the air-leak test area) was retained.

Overall results from these experiments are shown in Table 1, below.

Table 1. Throughput vs. Experiment \& Reject Rate

\begin{tabular}{|c|c|c|}
\hline Experiment & Reject Rate (\%) & Throughput \\
\hline 1 & $23 \%$ & 142.4 \\
\hline 1 & $15 \%$ & 190.4 \\
\hline 1 & $10 \%$ & 207.1 \\
\hline 2 & & \\
\hline 2 & $22 \%$ & 153.5 \\
\hline 2 & $20 \%$ & 167.8 \\
\hline & $18 \%$ & 179.7 \\
\hline 3 & & \\
\hline 3 & $20 \%$ & 156.0 \\
\hline 3 & $18 \%$ & 161.0 \\
\hline & $16 \%$ & 163.5 \\
\hline 4 & & \\
\hline 4 & $20 \%$ & 163.2 \\
\hline 4 & $18 \%$ & 174.4 \\
\hline & $16 \%$ & 184.6 \\
\hline
\end{tabular}

All comparisons between a pair of scenarios mentioned next were performed with a Student-t test (nine degrees of freedom, in view of ten replications per scenario) at the $5 \%$ significance level.

In conclusion, client engineers and management valued the following insights most highly: 
1. Comparing experiments 2 and 4 (at reject rates of $20 \%$ and $18 \%$ ), re-introducing engines and pallets from the cold test area decreased system throughput slightly (by about $2.8 \%$ ),

2. The bottleneck in all experiments, at all rejection rates, was the repair stations,

3. At air-leak test rejection rates of $18 \%$ or lower, this test line could reliably meet its target of 171.4 jobs per hour.

\section{CONCLUSIONS}

After combining the insights gained from this simulation study with other considerations involving the plant design as a whole, and constraints imposed by the upstream assembly line and the downstream cold-test line, client management chose an implementation design corresponding to experiment 4 . Furthermore, the client invested in a preventive maintenance program at the test stands which succeeded in maintaining the reject rate at $17 \%$. In actual production, this line then achieved a throughput rate of 179.2, slightly exceeding requirements and in good agreement with interpolation between 174.4 (model prediction of throughput at $18 \%$ reject rate) and 184.6 (model prediction of throughput at $16 \%$ reject rate).

\section{ACKNOWLEDGMENTS}

The authors gladly acknowledge the support and help of Chris DeWitt, project leader, and of Marcelo Zottolo, a colleague who provided guidance in the preparation and presentation of these results. Additionally, constructive criticism from four anonymous reviewers spurred useful improvements to this paper.

\section{REFERENCES}

Chramcov, Bronislav, and Ladislav Daníček. 2009. Simulation Study of the Short Barrel of the Gun Manufacture. In Proceedings of the $23^{\text {rd }}$ European Conference on Modelling and Simulation, eds. Javier Otamendi, Andrzej Bargiela, José Luis Montes, and Luis Miguel Doncel Pedrera, 275-280.

Chung, Christopher A. 2004. Simulation Modeling Handbook: A Practical Approach. Boca Raton, Florida: CRC Press.

Lang, Teresa, Edward J. Williams, and Onur M. Ülgen. 2008. Simulation Improves Manufacture and Material Handling of Forged Metal Components. In Proceedings of the $22^{\text {nd }}$ European Conference on Modelling and Simulation, eds. Loucas S. Louca, Yiorgos Chrysanthou, Zuzana Oplatková, and Khalid Al-Begain, 247-253.

Mehta, Arvind, and Ian Rawles. 1999. Business Solutions Using WITNESS. In Proceedings of the 1999 Winter Simulation Conference, eds. Phillip A. Farrington, Harriet Black Nembhard, David T. Sturrock, and Gerald W. Evans, 230-233.

Miller, Scott, and Dennis Pegden. 2000. Introduction to Manufacturing Simulation. In Proceedings of the 2000 Winter Simulation Conference, Volume 1, eds. Jeffrey A. Joines, Russell R. Barton, Keebom Kang, and Paul A. Fishwick, 63-66.
Seila, Andrew F., Vlatko Ceric, and Pandu Tadikamalla. 2003. Applied Simulation Modeling. Belmont, California: Thomson Learning, Incorporated.

Sargent, Robert G. 2004. Validation and Verification of Simulation Models. In Proceedings of the 2004 Winter Simulation Conference, Volume 1, eds. Ricki G. Ingalls, Manuel D. Rossetti, Jeffrey S. Smith, and Brett A. Peters, 17-28.

Sprent, Peter, and Nigel C. Smeeton. 2007. Applied Nonparametric Statistical Methods, $4^{\text {th }}$ edition. Boca Raton, Florida: Taylor \& Francis Group, LLC.

Ülgen, Onur, and Ali Gunal. 1998. Simulation in the Automotive Industry. In Handbook of Simulation: Principles, Methodology, Advances, Applications, and Practice, ed. Jerry Banks, 547-570.

Walker, Rob, Habrom Mebrahtu, and Caroline Strange. 2005. Achieving Efficiency Through Simulation in a Declining Manufacturing Market. In Proceedings of the 2005 Indusstrial Simulation Conference, eds. Jörg Krüger, Alexei Lisounkin, and Gerhard Schreck, 162-167.

Zeigler, Bernard P., Herbert Praehofer, and Tag Gon Kim. 2000. Theory of Modeling and Simulation: Integrating Discrete Event and Continuous Complex Dynamic Systems, 2nd edition. San Diego, California: Academic Press.

\section{AUTHOR BIOGRAPHIES}

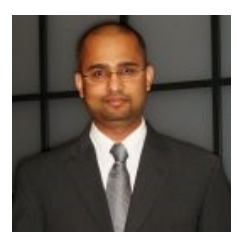

RAVI LOTE is a Consulting Project Manager at PMC. Over the last ten years, Ravi has built simulation models for dozens of customers in the U.S. and overseas. His functional areas of expertise include simulation modeling, process improvement and supply chain optimization. Ravi has a Bachelors' Degree in Mechanical Engineering from Shivaji University, India and a Masters' Degree in Industrial Engineering from the University of Massachusetts, Amherst. He is currently pursuing an M.B.A. from the University of Michigan, Ann Arbor. Ravi is a certified Six Sigma Black Belt and a certified MODAPTS ${ }^{\circledR}$ professional for conducting Industrial Engineering time studies.

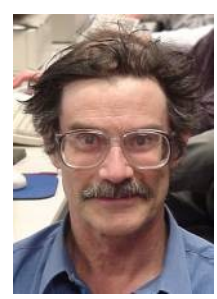

EDWARD J. WILLIAMS holds bachelor's and master's degrees in mathematics (Michigan State University, 1967; University of Wisconsin, 1968). From 1969 to 1971 , he did statistical programming and analysis of biomedical data at Walter Reed Army Hospital, Washington, D.C. He joined Ford Motor Company in 1972, where he worked until retirement in December 2001 as a computer software analyst supporting statistical and simulation software. After retirement from Ford, he joined PMC, Dearborn, Michigan, as a senior simulation analyst. Also, since 1980, he has taught classes at the University of Michigan, including both undergraduate and graduate simulation classes using GPSS $/ H^{\mathrm{TM}}$, SLAM II TM, SIMAN ${ }^{\mathrm{TM}}$, ProModel ${ }^{\mathrm{T}}$, SIMUL8 $\AA$, or Arena ${ }^{\circledR}$. He is a member of the Institute of Industrial Engineers [IIE], the Society for Computer 
Simulation International [SCS], and the Michigan Simulation Users Group [MSUG]. He serves on the editorial board of the International Journal of Industrial Engineering - Applications and Practice. During the last several years, he has given invited plenary addresses on simulation and statistics at conferences in Monterrey, México; İstanbul, Turkey; Genova, Italy; Rīga, Latvia; and Jyväskylä, Finland. He served as a co-editor of Proceedings of the International Workshop on Harbour, Maritime and Multimodal Logistics Modelling \& Simulation 2003, a conference held in Rīga, Latvia. Likewise, he served the Summer Computer Simulation Conferences of 2004, 2005, and 2006 as Proceedings co-editor. His email address is ewilliams@pmcorp.com.

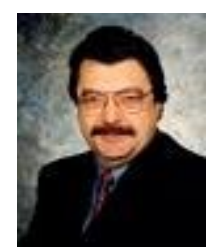

ONUR M. ÜLGEN is the president and founder of (formerly) Production Modeling Corporation (now PMC), a Dearborn, Michigan, based industrial engineering and software services company as well as a Professor of Industrial and Manufacturing Systems Engineering at the University of Michigan-Dearborn. He received his Ph.D. degree in Industrial Engineering from Texas Tech University in 1979. His present consulting and research interests include simulation and scheduling applications, applications of lean techniques in manufacturing and service industries, supply chain optimization, and product portfolio management. He has published or presented more that 100 papers in his consulting and research areas.

Under his leadership PMC has grown to be the largest independent productivity services company in North America in the use of industrial and operations engineering tools in an integrated fashion. PMC has successfully completed more than 3000 productivity improvement projects for different size companies including General Motors, Ford, DaimlerChrysler, Sara Lee, Johnson Controls, and Whirlpool. The scientific and professional societies of which he is a member include American Production and Inventory Control Society (APICS) and Institute of Industrial Engineers (IIE). He is also a founding member of the MSUG (Michigan Simulation User Group). 


\section{APPENDIX}

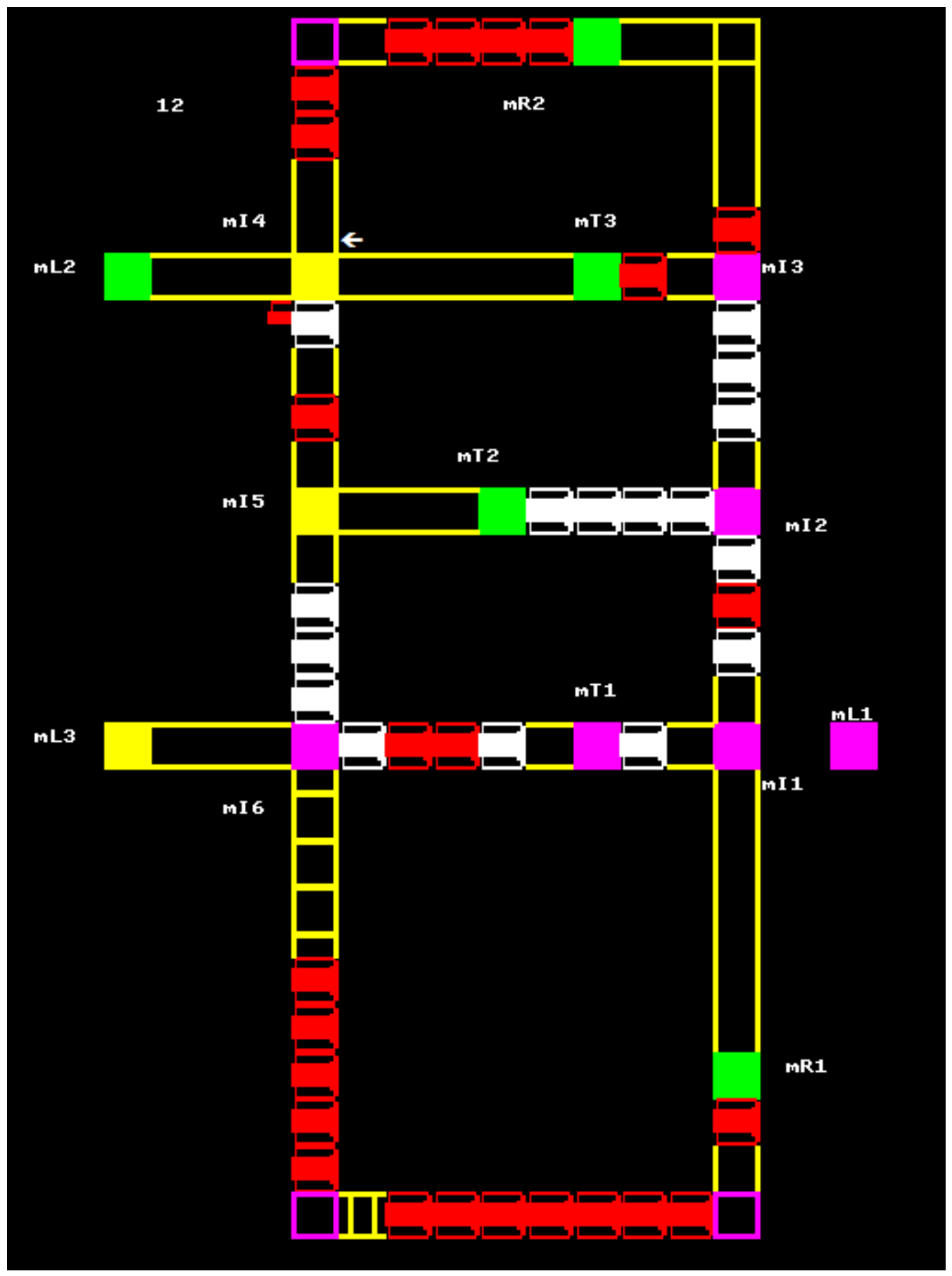

Figure 2. Screen Snapshot of WITNESS® Model

White engine icons represent engines that either have not yet been tested or passed their first test. Red engine icons (e.g. at bottom of snapshot) represent engines that have failed once.

Yellow engine icons (there is one at lower left corner) represent engines that have failed twice.

Black engine icons (there are none at the moment) represent engines that have failed three times. 